\title{
Economic Abuse: A Literature Review of a Salient yet Overlooked Form of Intimate Partner Violence
}

\begin{abstract}
Christa K. Haifley ${ }^{1}$
Economic abuse is another form of intimate partner violence (IPV) used by batterers to maintain power and control over their partners which often goes unreported, unrealized, and under-supported by IPV survivor advocates. Economic abuse is misunderstood as an IPV and is often incorrectly considered a financial crime, financial fraud, or white-collar crime. Economic abuse impacts the victim's short and long-term physical and mental well-being in efforts to achieve economic wellness for basic living conditions as well as job placement and professional development opportunities. Healthy minds fuel healthy bodies and economic self-efficacy contributes to both mental and physical health. The awareness and impact of economic abuse is grossly understudied, lacking empirical evidence on victims and survivors of economic self-sufficiency during and at the conclusion of an abusive relationship. The current research has primarily collected and reported data on heterosexual women, leaving a gap in the research regarding the impact of economic abuse in LGBTQ+ relationships. This paper serves as a literature review into current economic abuse research by discussing three constructs: economic control, economic exploitation, and employment sabotage as well as possible solutions for educational opportunities and financial self-efficacy. Further research is needed to raise awareness and provide financial literacy to IPV survivors in all gender communities. [Article copies available for a fee from The Transformative Studies Institute. E-mail address: journal@transformativestudies.org Website: http://www.transformativestudies.org (C2021 by The Transformative Studies Institute. All rights reserved.]
\end{abstract}

KEYWORDS: Economic Abuse, Intimate Partner Violence, Financial Literacy, Economic Self-Efficacy, LGBTQ+.

\footnotetext{
${ }^{1}$ Christa K. Haifley, Ph.D., is an Associate Accounting professor at SUNY Potsdam. Her current research interests include economic abuse, income inequality, eBook adoption, and developing financial literacy awareness and skills for all. Address correspondence to: Christa K. Haifley, e-mail: haifleck@potsdam.edu.
} 